\title{
Processability of Moist Superalloy Powder by SLM
}

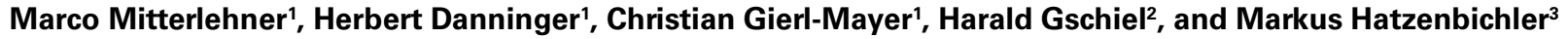

${ }^{1}$ Institut für Chemische Technologien und Analytik, TU Wien, Vienna, Austria

${ }^{2}$ voestalpine Böhler Edelstahl GmbH \& Co KG, Kapfenberg, Austria

${ }^{3}$ FOTEC Forschungs- und Technologietransfer $\mathrm{GmbH}$, Wiener Neustadt, Austria

Received November 13, 2020; accepted November 20, 2020; published online December 15, 2020

\begin{abstract}
Moisture is often claimed to be one of the main reasons for poor processability of powders when using L-PBF processes. To determine the influence of moisture on the processability, gas atomized superalloy powder IN718 has been printed in two parallel runs: once in the as-received and dry condition and once after four weeks of storage in an atmosphere containing a relative humidity of 75\%. Thereby different specimens have been prepared for notched impact tests, tensile tests, roughness, and metallographic analysis. Furthermore, the chemical composition of the powder before and after the build job as well as that of the printed parts have been analysed. The results obtained with the differently conditioned powders have been compared in the end to determine the influence of humidity on the processability on IN718 powder.
\end{abstract}

Keywords: Selective Laser Melting, Powder bed fusion, IN718, Moisture, Processability, Testing

\section{Verarbeitbarkeit von feuchtem Superlegierungspulver} mittels SLM

Zusammenfassung: Feuchte wird oft als einer der Hauptgründe für schlechte Verarbeitbarkeit von Pulvern mittels L-PBF Prozessen angeführt. Um den Einfluss der Feuchte auf die Verarbeitbarkeit zu untersuchen, wurde ein inertgasverdüstes Superlegierungspulver IN718 in zwei parallelen Durchläufen gedruckt: einmal im Anlieferungszustand und somit trocken und einmal nach vierwöchiger Lagerung in einer Atmosphäre mit einer relativen Luftfeuchtigkeit von $75 \%$ und somit feucht. Dabei wurden verschiedene Proben für Kerbschlagbiegeversuche, Zugversuche, Rauhigkeitsmessungen und metallographische Analysen hergestellt. Darüber hinaus wurde die chemische Zusammenset-

M. Mitterlehner ( $₫)$

Institut für Chemische Technologien und Analytik, TU Wien,

Getreidemarkt 9/164-CT,

1060 Vienna, Austria

marco.mitterlehner@tuwien.ac.at zung des Pulvers vor und nach dem Druck sowie die der gedruckten Teile analysiert. Die Ergebnisse der Versuche mit unterschiedlich konditionierten Pulvern wurden schließlich verglichen, um den Einfluss der Feuchtigkeit auf die Verarbeitbarkeit von IN718 Pulver zu bestimmen.

Schlüsselwörter: Selektives Laserschmelzen, Pulverbetttechnologie, IN718, Feuchte, Verarbeitbarkeit, Testen

\section{Introduction}

Nickel-based superalloys have been widely used in the aerospace and energy industries and, as they are difficult to process in particular through machining, near-netshape processing techniques, such as additive manufacturing of these materials, have gained more and more popularity over the last decades [1, 2]. These materials combine high-temperature strength, toughness, corrosion resistance, and good fatigue life [3]. Yet, these properties depend on the microstructure. Due to the fact that during additive manufacturing the selectively melted material rapidly cools down and thereby solidifies, the resulting microstructure as well as subsequent heat treatments are of particular importance to precipitate the strength-enhancing phases in the matrix and thus to achieve conventional mechanical properties of wrought and cast forms [4-8]. Specimens built by selective laser melting (SLM) typically show anisotropic mechanical properties, a fact which has to be taken into account when producing components by SLM [6, 7].

In laser powder bed fusion technologies, humidity is often claimed to be a huge problem. In [9], moisture inside the printing chamber is associated with the formation of pores in the built component, whereby some materials such as aluminium alloys are more affected than others, like an investigated nickel-based superalloy (IN718). Apart from the particle size and shape of a powder, which can influence powder characteristics such as the flowability, adsorbed water on the powder surface is often claimed as detrimen- 
tal [10-12]. In order to quantify the water adsorption on the powder surface, various attempts have been made in the recent past, whereby the analysis by Karl Fischer titration appears to be the most reliable one [13, 14].

To investigate the impact of adsorbed water on the processability of a gas atomized IN718 powder, two build jobs were carried out in the present study. The powder was once processed in a dry initial state and once in a humid state. Thereby, tensile and Charpy impact test specimens as well as simple cubes were built. The first two were then machined to test geometries, whereas the cubes were investigated in the as built state. Thus, the impact of moisture on the mechanical properties, surface roughness, density, porosity, microstructure, and hardness of the printed components was investigated. The interstitial content as well as the particle size distribution of the powder before and after each build job were also determined. In addition, the chemical bulk composition of the powder as well as that of the built specimens was analysed to determine whether any print-related changes were present.

\section{Experimental Procedure}

\subsection{Powder Used}

For this study, an inert gas atomized IN718 powder grade from voestalpine Böhler Edelstahl GmbH \& Co KG, available under the designation L718 AMPO, was used. In Fig. 1 the mass-related particle size distribution measured using laser diffraction by a Sympatec HELOS/BF system is shown. There it can be seen that the distribution is minimally left skewed but very uniform and narrow. The particle size is in the range of about $15-55 \mu \mathrm{m}$. The mass median diameter $\left(d_{3}, 50\right)$ of the powder is $30.43 \pm 0.10 \mu \mathrm{m}$.

An SEM image of the L718 AMPO powder used, taken with a JEOL JCM-6000, is shown in Fig. 2. Most of the par-

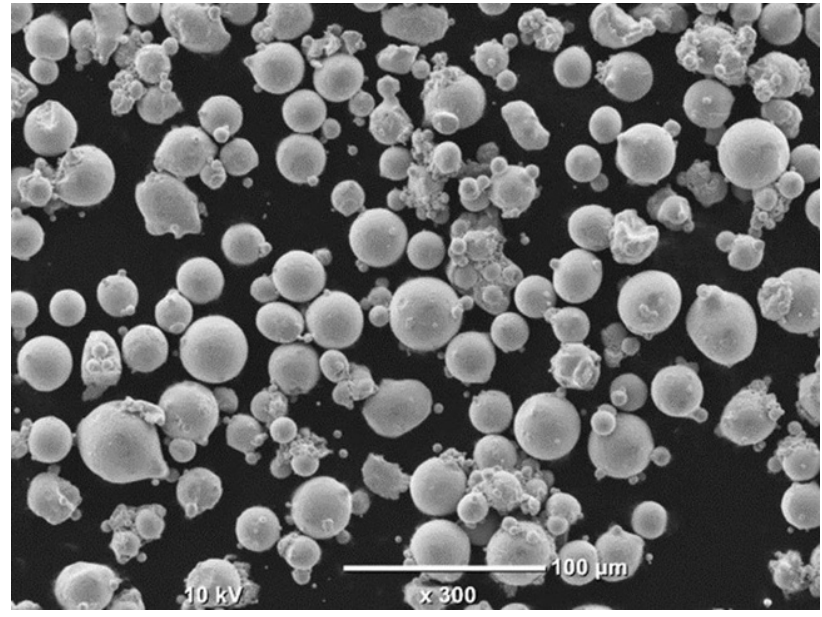

Fig. 2: SEM image of the used L718 AMPO powder

ticles are well spherical but, nevertheless, there are also a few non-spherical particles and fused agglomerates of smaller particles $(<10 \mu \mathrm{m})$. Furthermore, the particles are also partially covered with satellites, and yet, the overall shape is considered to be more or less spherical and uniform.

When measuring the flow time according to ISO 4490:

2018, it was found that the powder did not flow freely through the calibrated Hall funnel. Nevertheless, it could be spread and processed during printing without any problems.

Before the first and after each build job, a powder sample was taken from the centre of the powder bed to measure the particle size distribution using dynamic image analysis by a CAMSIZER $\mathrm{X} 2$, to determine the interstitial contents $(\mathrm{C}, \mathrm{N}, \mathrm{O}, \mathrm{H})$, and to analyse the chemical bulk composition using ICP-OES.
Fig. 1: Mass-related particle size distribution of the used L718 AMPO powder

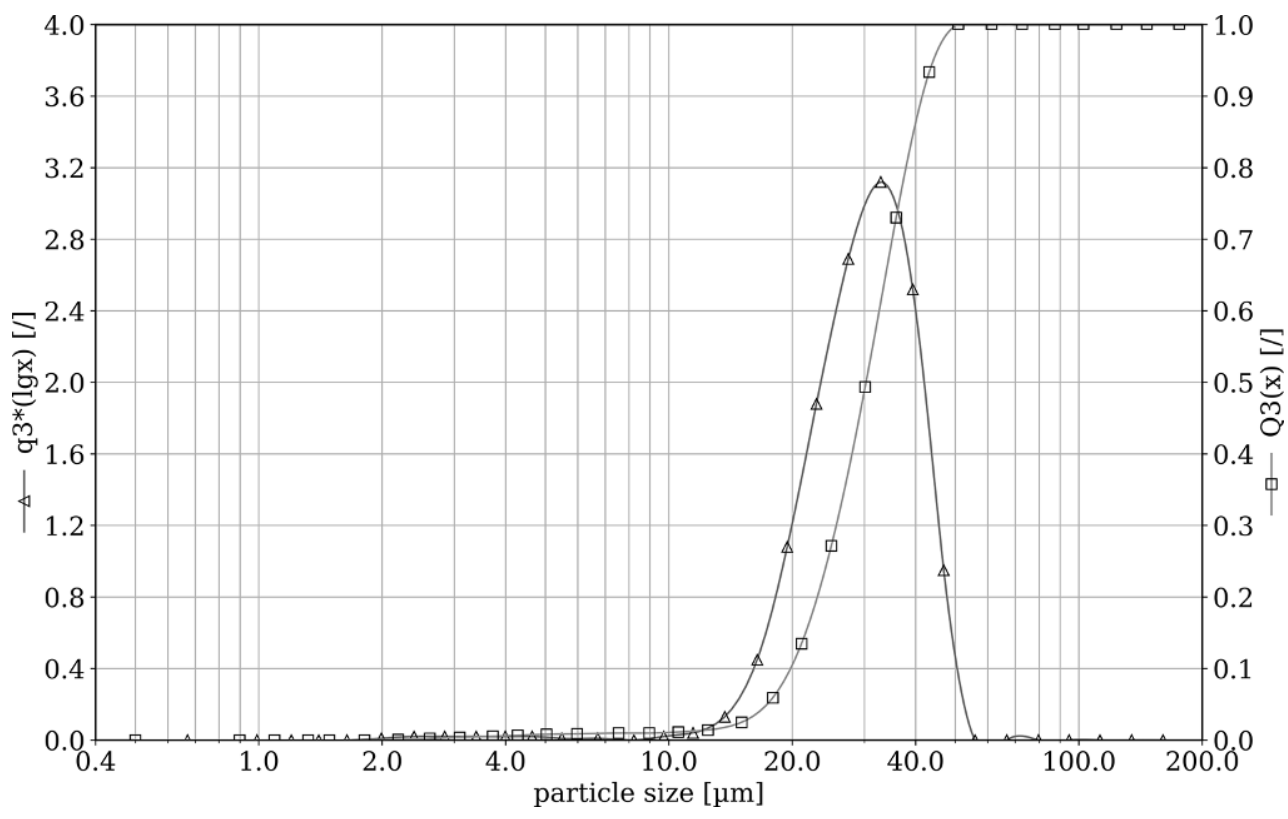




\subsection{Powder Conditioning}

To investigate the impact of adsorbed water on the processability of the used powder, it was conditioned once in a dry and once in a humid state. The dry state is defined as the state in which the powder is still in its original packaging. This is because there is also a bag with a drying agent in the powder container intended to remove all moisture from the environment, thus making the powder "dry". As soon as the first build job is done, the sealed powder container is opened, and the powder is filled directly into the machine.

After the first build job, the remaining powder was removed from the machine and transferred to several powder containers. The powder was then stored in these containers for a total of four weeks on site. Using a saturated sodium chloride solution, which was stored in the containers in parallel to the powder, a relative humidity of $75 \%$ was achieved [15]. During storage a sample was taken twice a week to measure the water uptake of the powder using an AQUATRAC-V mobile moisture measuring unit, which is usually used for polymers and works according to ISO 15512:2019. Therefore, it was checked if this device is also suitable for metal powders. The main difference lies in the physical water uptake. For polymers the water is absorbed, whereas for metal powders it is only adsorbed. Thus, desorption by a change of the surrounding atmosphere can happen quite fast for metals but not for polymers. Also, when taking this sample, the powder was carefully stirred. After four weeks the powder was conditioned in the humid state and was therefore used for the second build job.

\subsection{SLM Build Jobs}

For printing, an EOS M280 SLM machine at FOTEC GmbH (Wiener Neustadt) was used. This SLM printer works with an ytterbium fibre laser with $200 \mathrm{~W}$ output power at a wavelength of $1080 \mathrm{~nm}$. The scanning strategy was set to an alternating raster, in which each subsequent layer is rotated $67^{\circ}$ from the previous one. Furthermore, in each layer, first the contour and then the inner body were melted in order to achieve better surface qualities. The layout of the built specimens on the building platform can be seen in Fig. 3 .

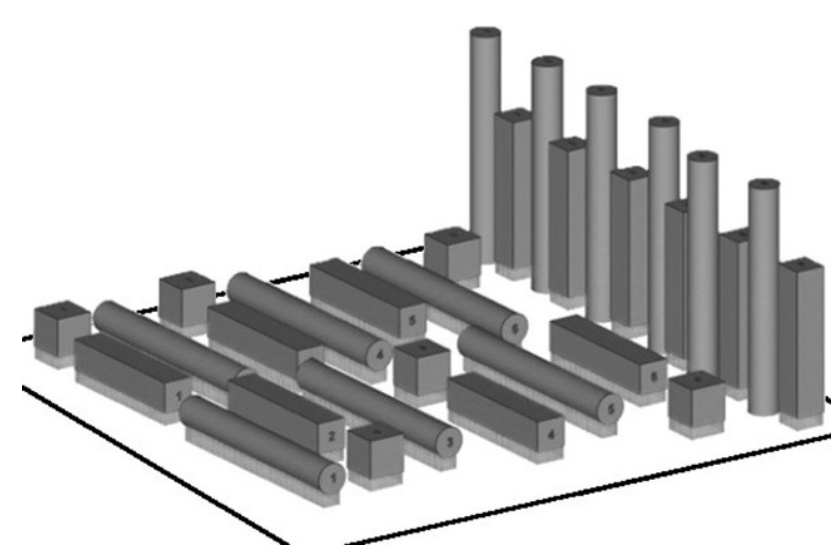

Fig. 3: Building platform layout

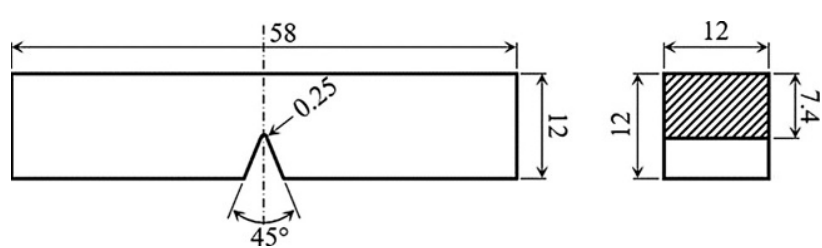

Fig. 4: Machined Charpy impact specimen (dimensions in $\mathrm{mm}$ )

As depicted there, a total of six cubes was produced, and six Charpy impact (cuboids) and tensile (cylinders) test specimens each were built horizontally as well as vertically. For printing, a layer thickness of $40 \mu \mathrm{m}$ and a spreading velocity of $150 \mathrm{~mm} / \mathrm{s}$ were used. During the build job, the building platform was heated up to $40^{\circ} \mathrm{C}$, and a dry nitrogen atmosphere generated by the machine itself was introduced.

\subsection{Reworking Specimens and Equipment for Charpy Impact Test}

Additive manufactured components have a high surface roughness compared to machined ones, which is significant as it impairs the mechanical properties [16-20]. Thus, the specimens were laser manufactured oversized and then machined to the specified dimensions as shown in Fig. 4. The measurements were carried out using a PSW750 pendulum impact testing machine from HKE GmbH with a potential energy of $750 \mathrm{~J}$ as well as a TZE $3020 \mathrm{HA}$ pendulum impact testing machine from $\mathrm{R}+\mathrm{K}$ Amsler. In both machines a $2 \mathrm{~mm}$ striking fin was used.

\subsection{Reworking Specimens and Equipment for Tensile Testing}

As with the impact test specimens, the tensile specimens were produced slightly oversized and then machined to shape as shown in Fig. 5. The cross-section of the reworked specimens in this case was circular. The measurements were carried out using a BETA 400-2 material testing machine from Messphysik Materials Testing $\mathrm{GmbH}$.

In addition, a small part of one of the specimens from the second (humid) build job was cut after testing. This was then used for the analysis of the chemical composition using ICP-OES to check whether there have been any changes as a result of the build job in the additively manufactured material compared to the powder used.

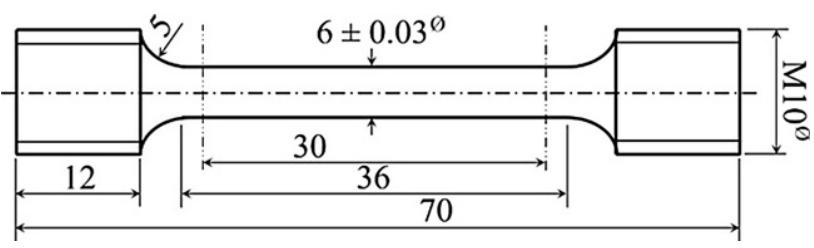

Fig. 5: Machined tensile specimen (dimensions in $\mathrm{mm}$ ) 

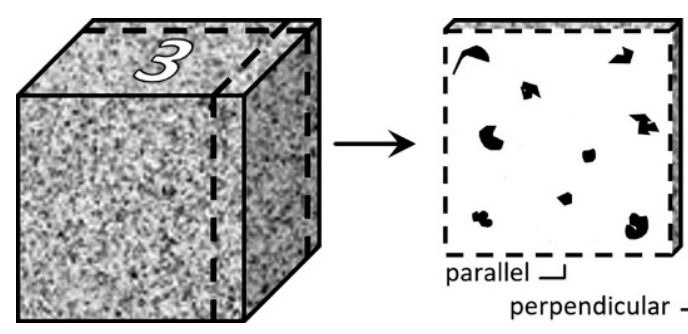

perpendicular -

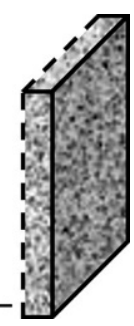

Fig. 6: Cutting scheme

\subsection{Investigation of the Cubes}

The density cubes were examined in different ways. First, the surface roughness of the cubes in the as-built state was measured using an Alicona InfiniteFocusSL with $10 \times$ magnification. Thereby all side surfaces were examined according to ISO 4287 and 4288 . Then the density of the cubes was determined according to Archimedes' principle (assuming that exclusively closed porosity was contained). After that the cubes were cut parallel and perpendicular to the spreading direction as shown in Fig. 6. Using these, two metallographic samples for each cube were prepared.

In the unetched state, the cut surfaces were first checked for porosity. To do so, the entire cross-section was depicted using a Keyence VHX-5000 digital microscope with $100 \times$ magnification. Next, the image was converted into a black-and-white image, then cut so that the embedding material was not visible anymore, and a threshold was set. Finally, the amount of the black area in the image refers to the amount of porosity. This scheme is also shown in Fig. 7.

After checking the porosity, the microhardness (Vickers, standard ISO 6507-1:2018) was determined using a load of $0.1 \mathrm{~N}$. The tests were carried out using an AHOTEC ecoHARD XM 1270A hardness tester. Thereby, the hardness was determined nine times in the centre and on eight positions in the edge area of the cut surface as shown in Fig. 8.

The microstructure was examined first using an SEM FEI Quanta 200 with coupled EDX detector. Finally, the metallographic samples were etched using a mixture of aqua regia and $1 \mathrm{wt} \%$ conc. hydrofluoric acid. The etching reagent was only applied for a few seconds and washed away immediately afterwards with water. The etched samples were then observed on an Olympus GX 51 inverted light microscope including digital camera for image acquisition. Images were taken in the centre and in the edge area of the surface. In addition, the samples were examined by X-ray diffraction using an $\mathrm{X}^{\prime} \mathrm{Pert}^{2}$ Pro MPD X-ray diffraction sys-

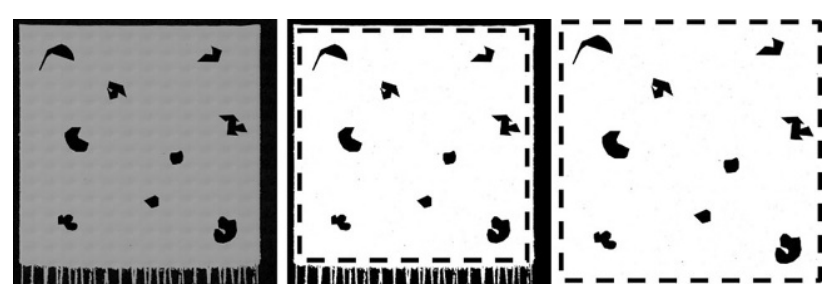

Fig. 7: Porosity measurement
Fig. 8: Test spots

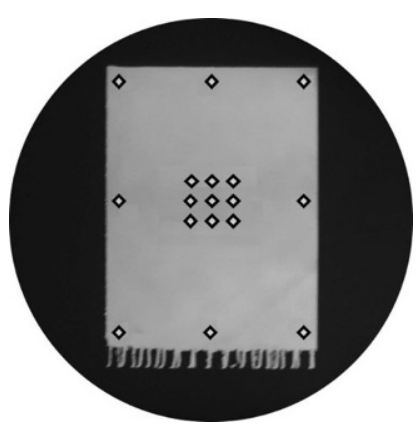

tem with a Cu- $\mathrm{K}_{\alpha} \mathrm{X}$-ray source and the evaluating software "HighScore" from Malvern Panalytical to get information about the phases present.

\section{Results and Discussion}

\subsection{Moisture Uptake of the Powder}

In order to expose the powder properly to the desired relative humidity, it had to be stored in three different containers. During storage, however, there was no significant change in the adsorbed water content in any of the three containers, just a high scatter could be observed as shown in Fig. 9. It is therefore assumed that the adaptation of the powder to the atmosphere caused by the change in relative humidity of the air when taking a sample out of the container for analysis happens so rapidly that much of the water has already been-more or less uncontrollably-desorbed at the time of measurement. Since in [21] this type of conditioning was already applied and the influence of moisture on the flow time was investigated, it is concluded that this analysing method as described in Sect. 2.2. is just not suitable for metal powders.

\subsection{Interstitial Content of the Powder}

As can be seen in Fig. 10, there are no significant changes in carbon, nitrogen, oxygen, or hydrogen content when comparing the as-received state (before the first build job) and the state of the powder after the first (dry) and second (humid) build job.

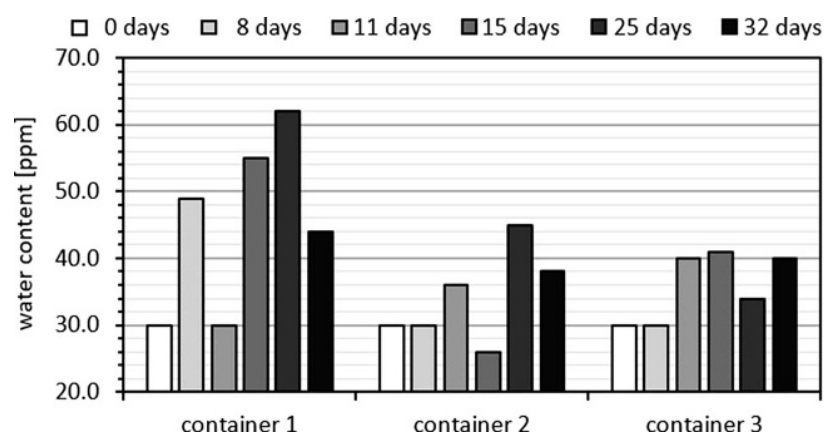

Fig. 9: Adsorbed water content of the powder during storage 


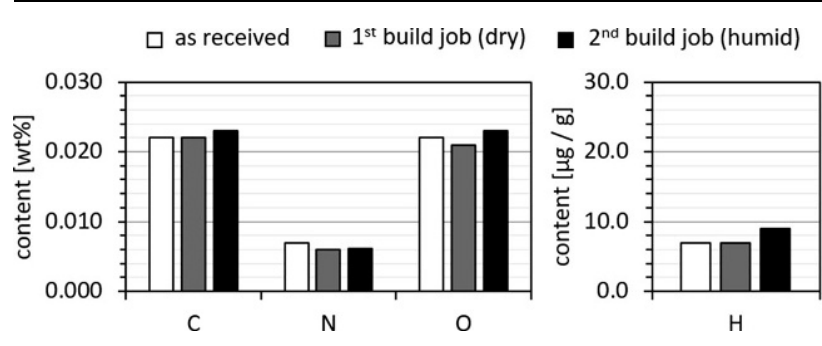

Fig. 10: $\mathrm{C}, \mathrm{N}, \mathrm{O}$ and $\mathrm{H}$ content of the powder before and after printing

\begin{tabular}{|c|c|c|c|}
\hline \multicolumn{4}{|c|}{$\begin{array}{l}\text { TABLE } 1 \\
d_{3,10^{-}}, d_{3,50^{-}} \text {and } d_{3,90^{-}} \text {values before and after printing }\end{array}$} \\
\hline Condition & $\begin{array}{l}\mathrm{d}_{3,10} \\
{[\mu \mathrm{m}]}\end{array}$ & $\begin{array}{l}\mathrm{d}_{3,50} \\
{[\mu \mathrm{m}]}\end{array}$ & $\begin{array}{l}\mathrm{d}_{3,90} \\
{[\mu \mathrm{m}]}\end{array}$ \\
\hline As received & 21.2 & 31.1 & 40.7 \\
\hline 1st build job & 21.0 & 31.5 & 41.9 \\
\hline 2nd build job & 21.3 & 30.6 & 40.5 \\
\hline
\end{tabular}

\subsection{Particle Size Distribution of the Powder}

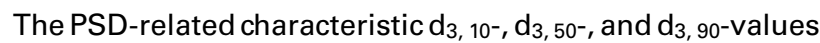
are listed in Table 1. As can be seen, hardly any changes resulted from the two build jobs. Since the shapes of the distribution graphs are more or less equal, they are not shown. Thus, it is concluded that no significant changes in the particle size distribution are caused by only these two build jobs.

\subsection{Mechanical Properties of the Printed Specimens}

In both Fig. 11 and Table 2, the results of the tensile and Charpy impact specimens tested are shown. As already observed in many other studies, there is a difference referred to the building direction. The horizontally built specimens revealed a higher ultimate tensile strength, yield strength and impact strength and a lower elongation while the vertically built ones show less strength but higher ductility. This indicates that the difference is not caused by variations in the integrity of the specimens as the bonding defects between the layers would have had an adverse effect on the elongation in particular, which is not the case, however. Therefore, it is assumed that these differences originate firstly from different heat treatment states-as the vertically built specimens were exposed to the laser more often -, secondly from a different amount of residual stresses

\begin{tabular}{|c|c|c|c|}
\hline \multicolumn{4}{|c|}{$\begin{array}{l}\text { TABLE } 2 \\
\text { Measured and literature values of ultimate tensile } \\
\text { strength (UTS), yield strength (YS) and elongation }\end{array}$} \\
\hline Build direction & $\begin{array}{l}\text { UTS } \\
\text { [MPa] }\end{array}$ & $\begin{array}{l}\mathrm{YS} \\
{[\mathrm{MPa}]}\end{array}$ & $\begin{array}{l}\text { Elongation } \\
{[\%]}\end{array}$ \\
\hline $\begin{array}{l}\text { Horizontal 1st build } \\
\text { job }\end{array}$ & $1082 \pm 5$ & $804 \pm 7$ & $27 \pm 0$ \\
\hline $\begin{array}{l}\text { Horizontal 2nd build } \\
\text { job }\end{array}$ & $1082 \pm 1$ & $803 \pm 3$ & $27 \pm 1$ \\
\hline Vertical 1st build job & $993 \pm 27$ & $659 \pm 31$ & $34 \pm 1$ \\
\hline Vertical 2nd build job & $989 \pm 26$ & $656 \pm 31$ & $34 \pm 1$ \\
\hline Horizontal [6] & $\sim 1080$ & $\sim 790$ & $\sim 31$ \\
\hline Vertical [6] & $\sim 990$ & $\sim 620$ & $\sim 36$ \\
\hline Horizontal [7] & 1158 & 846 & 21.5 \\
\hline Vertical [7] & 1114 & 710 & 24.5 \\
\hline
\end{tabular}

inside the specimens due to the rapid cooling, and thirdly from a columnar grain growth parallel to the build direction, which causes a weak texture inside the samples so that the direction of the applied tensile force has a non-negligible influence on the properties, as described in [7]. Regarding the conditioning states of the powder, dry vs. humid storage, no significant difference could be observed, except for the impact strength which minimally decreased but only with high scatter. As a reference, also some literature values are listed in Table 2. It can be seen that the values are generally in the same range. Thus, both conditioned powders could be processed to sound bodies with the used SLM conditions regardless of previous dry or humid storage.

\subsection{Surface Roughness}

The layout of the cubes on the building platform as well as the direction of spreading and gas flow can be seen in Fig. 12. The side faces were thereby termed "North", "East", "South", and "West". Then, if the surface exhibited larger protrusions and irregularities, it was avoided to measure across these in order not to falsify the results. The results of the arithmetical mean roughness $\left(R_{a}\right)$ measurement on the top face and therefore on the last spread and selectively melted layer is depicted in Fig. 13. Regarding the different conditioning of the powders, no consistent difference in roughness could be observed here, i.e. storage in humid atmosphere does not have any effect. Regarding the ar-
Fig. 11: Ultimate tensile strength (UTS), yield strength (YS), elongation and impact strength of the printed specimens

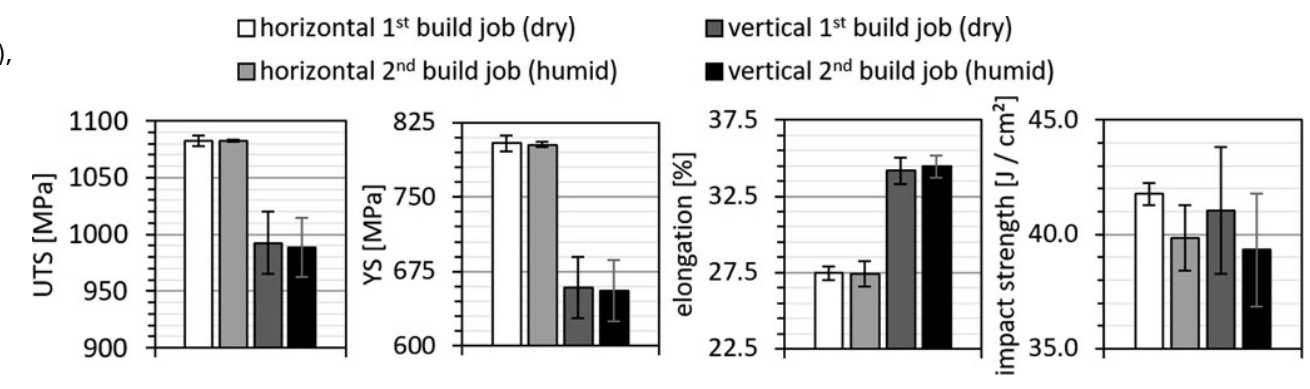




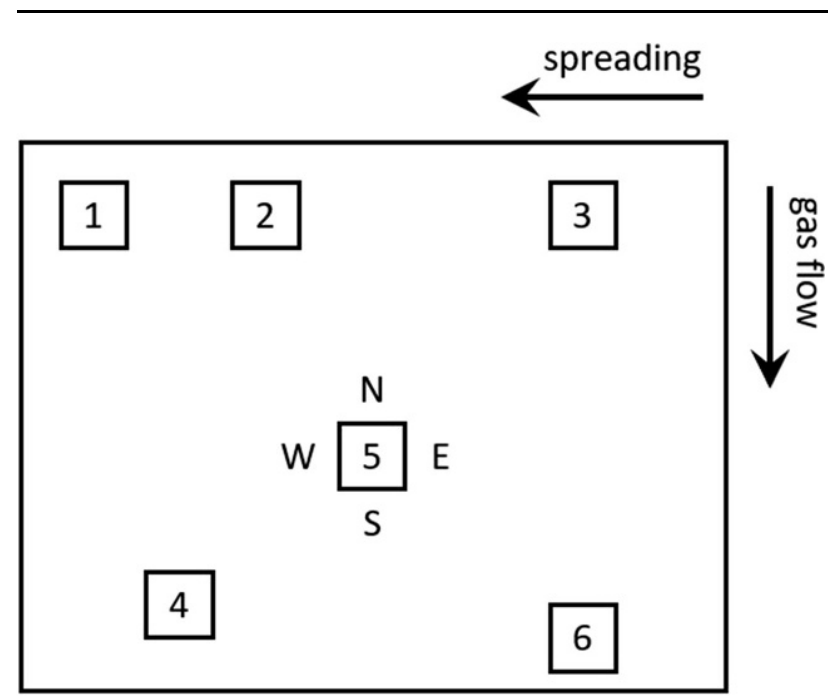

Fig. 12: Cubes on building platform

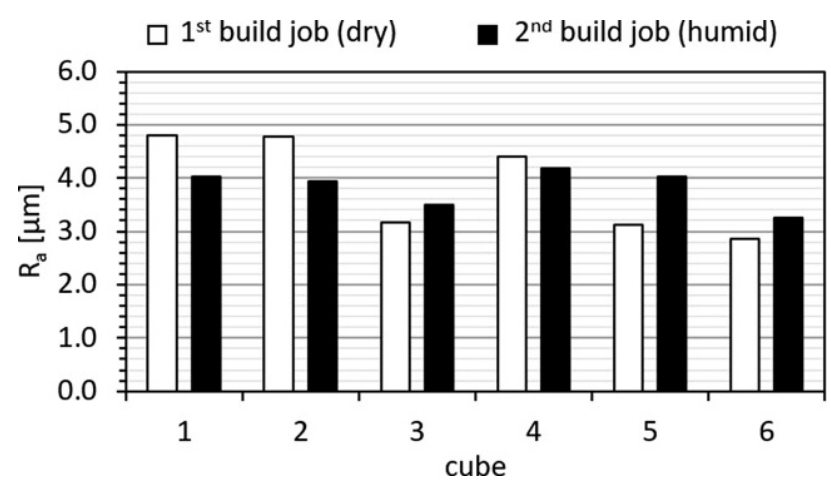

Fig. 13: $R_{a}$ of the cube top face

rangement of the cubes, however, the following trend can be observed: the further to the right the smoother the surface is, when comparing Cubes 1,2 , and 3 as well as 4,5 , and 6 . Thus, the closer the cube was built to the starting point of spreading, the smoother the surface was. The reason is probably the segregation in the spread powder layer. As the powder bed of the EOS M280 machine is quite long, it might happen that in the beginning preferably smaller particles remain in the powder layer. These are then missing at the end of the powder bed, which coarsens the particle size distribution and further influences the surface roughness of the built parts. Yet, currently this is just a hypothesis.

The lowest $\left(R_{a}\right.$ low $)$ and highest $\left(R_{a}\right.$, high $)$ measured roughness values on the side faces are shown in Figs. 14 and 15, with reference to the measured side on the x-axis. Again, regarding the different conditioning of the powders, no consistent difference in roughness could be observed. Considering the smoothest sides, these are located on the east side for almost each cube (except the one on position 6), which is the side from which the recoater blade comes when spreading the powder. Considering the roughest sides, no such consistent trend could be observed. Yet, it is noticeable that, always in both build jobs, the same sides of the same cubes show the lowest and highest roughness.

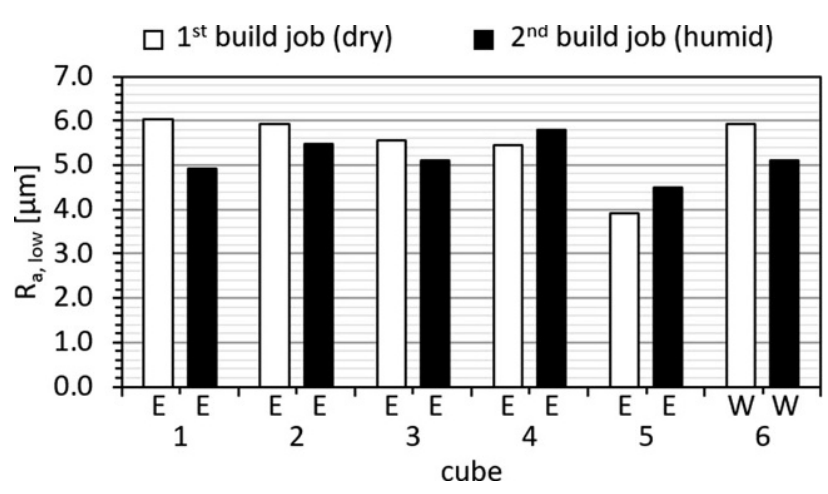

Fig. 14: Lowest $R$ a of the cube side faces

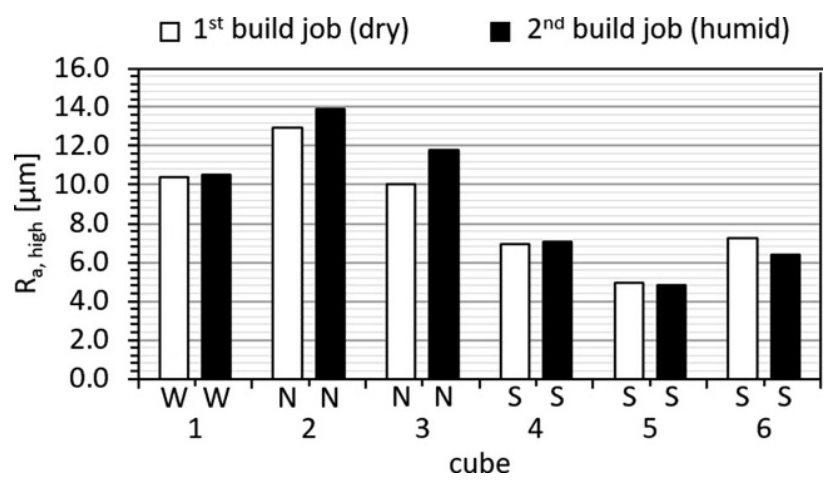

Fig. 15: Highest $R_{a}$ of the cube side faces

\subsection{Density}

From the measured density shown in Fig. 16, no correlation-neither to the different conditioning states of the powder nor to the arrangement of the cubes on the building platform - can be observed. Thus, the average density was calculated, which is $8.20 \pm 0.00 \mathrm{~g} / \mathrm{cm}^{3}$ for the first and $8.20 \pm 0.01 \mathrm{~g} / \mathrm{cm}^{3}$ for the second build job, which fits perfectly with the nominal density of $8.20 \mathrm{~g} / \mathrm{cm}^{3}$ according to the datasheet for this material.

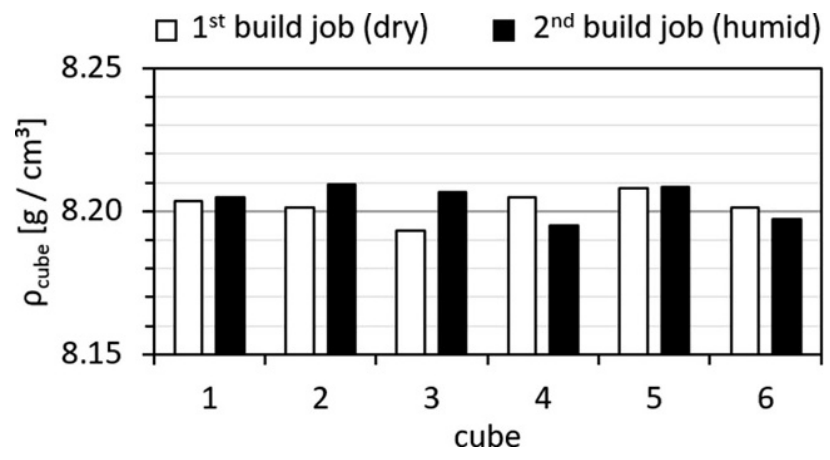

Fig. 16: Density of the cubes 
Fig. 17: Porosity of the cubes

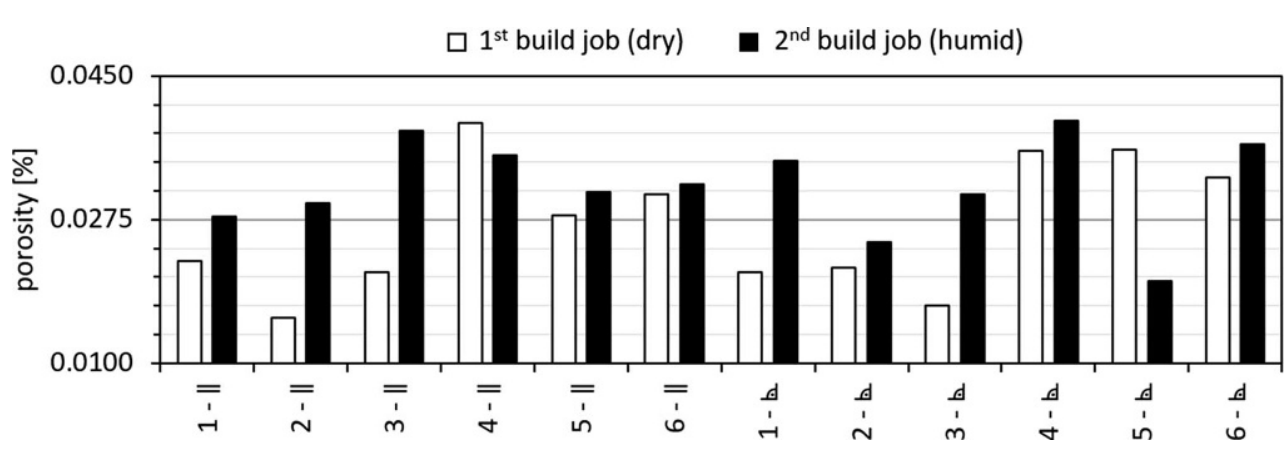

\subsection{Porosity}

The estimated porosity parallel and perpendicular to the spreading direction of the prepared metallographic samples is shown in Fig. 17. As with the density, no trends related to either conditioning state or the arrangement of the cubes on the building platform or the direction of the examined cross-section can be observed. Overall, the cubes were about $99.971 \%$ dense on average, which is very satisfactory.

\subsection{Hardness}

As can clearly be seen in Fig. 18, the hardness measured at the edge (white) of the cubes is always significantly lower than the one measured in the centre (black). It is assumed that this is caused by a temperature gradient inside the built cube during fabricating, which results in an intrinsic heat treatment. In the observation of the microstructure, however, no findings were made that would confirm this assumption. No clear trends could be observed when comparing the hardness of the various conditioning states of the powders, the different directions of the examined crosssections, or the arrangement of the cubes on the building platform. An average value of $325 \mathrm{HVO} .3$ can be found in the literature [22], which is in very good agreement with the values measured here.

\subsection{Microstructure}

The etched vertical cross-sections in Fig. 19 did not reveal any significant difference in the microstructure depending on the examined location (centre vs. edge). By comparing the parallel and perpendicular cross-sections, the different

Fig. 18: Hardness of the cubes

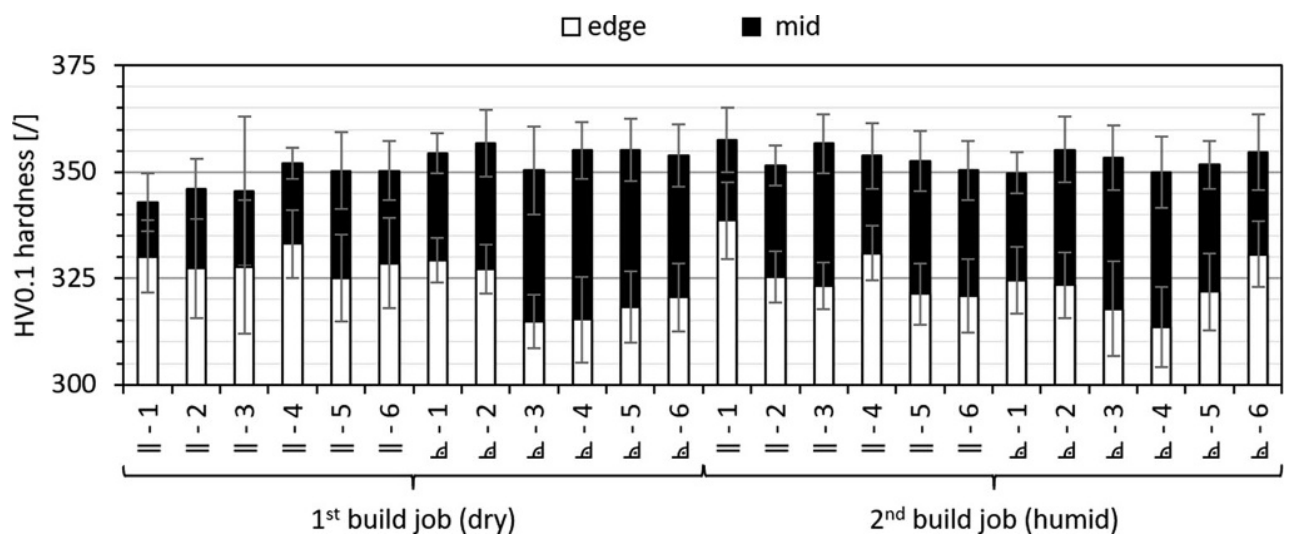

Fig. 19: Etched cross-section in the centre (left) and on the upper edge (right) of a cube
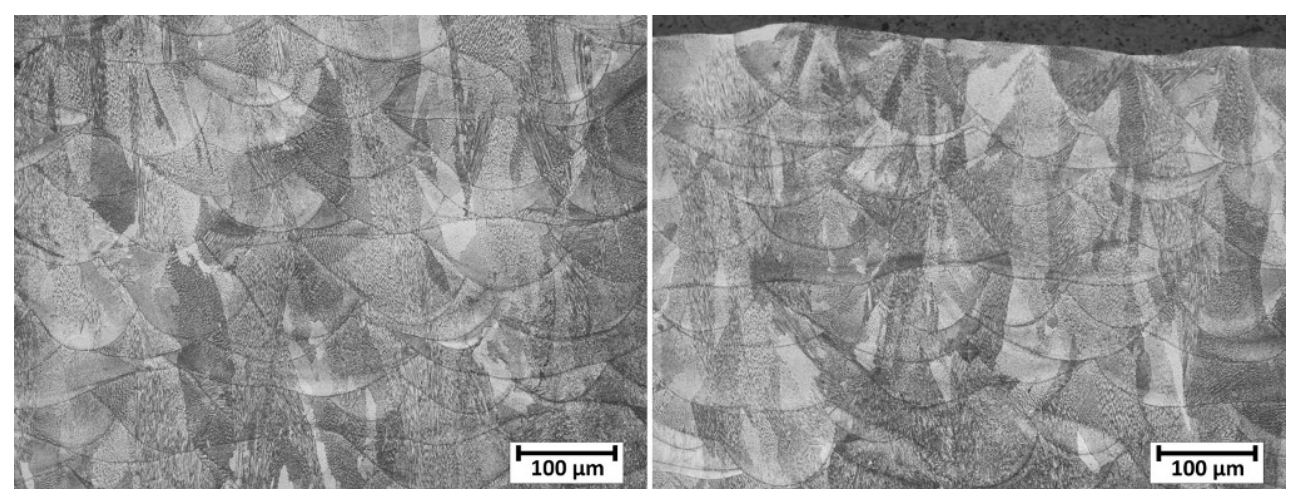


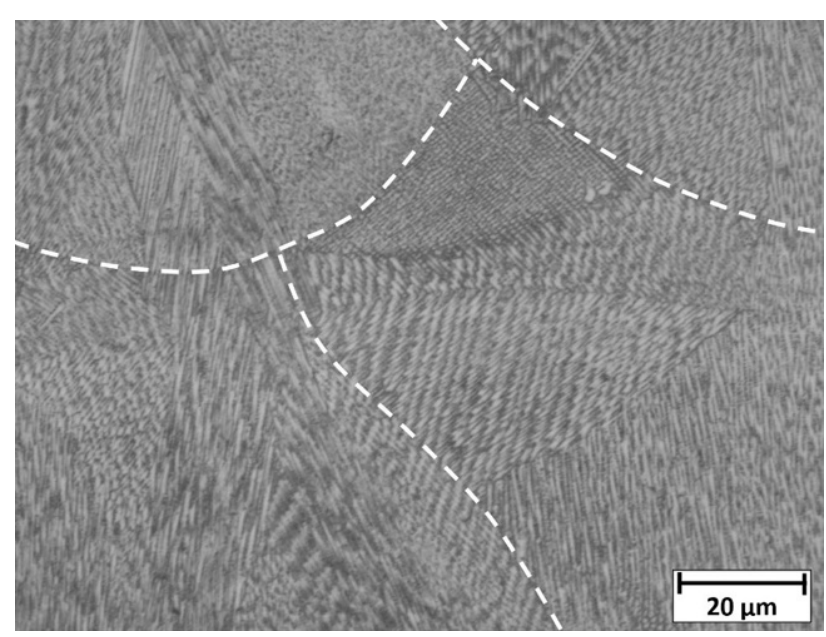

Fig. 20: Zoomed in image of an etched cross-section with marked laser tracks

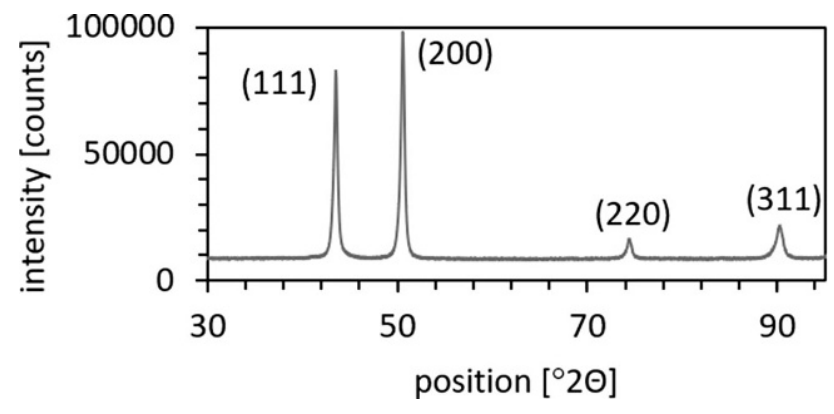

Fig. 21: Diffractogram of a cube positions, or the various conditioning states of the powder, there are no differences, so the images are not shown here. Etching clearly shows the single laser tracks, and when zooming in, several grains can be observed within the laser tracks, as marked with a white dashed line in Fig. 20. Within these grains, very fine cellular dendrites are present with exclusively primary dendrite arms (dark area).

To identify the overall present phases, an XRD analysis was carried out. In the acquired diffractogram in Fig. 21 only peaks from an fcc crystal structure were found, which can be assigned to the $\gamma$-phase and $\gamma^{\prime}$-phase. Thus, the strengthening $\gamma^{\prime \prime}$-phase is missing in the pattern.

To correctly assign the phases in the observed microstructure to those identified by XRD, a line scan quantifying the elements $\mathrm{Nb}, \mathrm{Al}, \mathrm{Ti}, \mathrm{Cr}$, $\mathrm{Fe}$, and $\mathrm{Ni}$ was performed on the cross-section of a cube. The path of the line scan is marked in Fig. 22 by a white line, which crosses these white stripes, which is the interdendritic space. The quantified data below shows that, in the brighter areas (interdendritic space), $\mathrm{Nb}, \mathrm{Al}$, and $\mathrm{Ti}$ are enriched, whereas, in the darker areas (dendrites), $\mathrm{Ni}, \mathrm{Fe}$, and $\mathrm{Cr}$ are enriched, which can be assigned to the $\gamma$-phase that makes up the matrix. Thus, the alloying elements that are responsible for forming the strengthening precipitates like the $\gamma^{\prime}$ - or $\gamma^{\prime \prime}$-phase are enriched in the interdendritic space and are therefore missing in the matrix, as already described in [23]. Several heat treatments are available to precipitate them and have already been validated using additively manufactured specimens [6, 23-25].
Fig. 22: EDXline scan on the cross-section of a cube

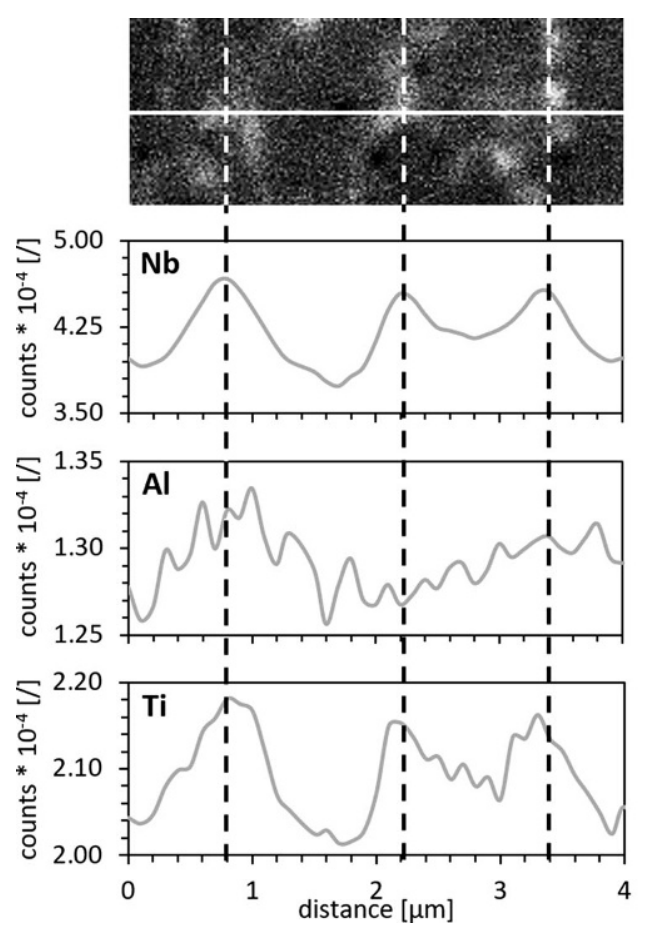


Fig. 23: Chemical bulk composition measured by ICP-OES $\square$ conc. according to data sheet $\square$ as received $\square$ powder $1^{\text {st }}$ build job (dry)

$\square$ powder $2^{\text {nd }}$ build job (humid) $\quad$ printed part $2^{\text {nd }}$ build job (humid)

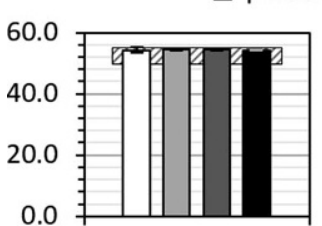

$\mathrm{Ni}$

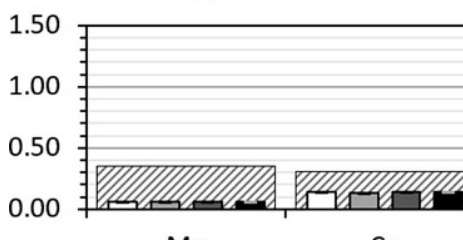

$\mathrm{Cu}$

$\mathrm{Mn}$

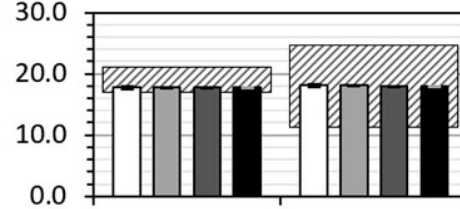

$\mathrm{Cr}$
$\mathrm{Fe}$

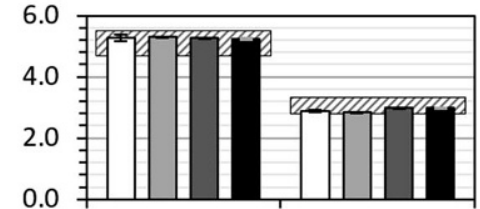

$\mathrm{Nb}$

Mo

Co

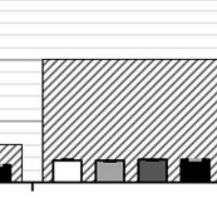

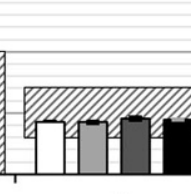

Al

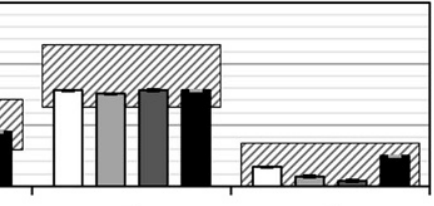

$\mathrm{Ti}$

Si

\subsection{Chemical Bulk Composition (ICP-OES)}

In Fig. 23 the chemical bulk composition of the analysed powder and the printed specimen can be seen. In the background, the respective concentration range according to the manufacturer is marked by the grey hatched area. Thus, there is no change in concentration of the individual elements, neither in case of the powder nor in case of the printed specimen. The latter means that there is no loss of alloying elements through this type of production, which is crucial (as e.g. observed in EBM of Ti aluminides). Furthermore, the concentration values are always within the specified range.

\section{Summary}

In this study it was found that the used method for determining the adsorbed water on metal powders was unsuitable due to quick desorption before a measurement can be made. This is also concluded to be the main reason why there are no differences in any tests caused by the various conditioning states of the L718 AMPO powder used. Here it is important to mention that filling the powder into the machine takes around $30 \mathrm{~min}$, and flooding and purging of the process chamber to establish the required low oxygen level takes another $30-45 \mathrm{~min}$. The conditioned powder was thus not processed until about an hour later and therefore had sufficient time to adapt to its environment, especially to shed the adsorbed water.

Once more it was shown that the Hall funnel flow test is not an appropriate method for testing powders used for L-PBF technologies, as the powder did not flow but could be spread and processed without any problems. Regarding the particle size distribution and the interstitial contents of the powder, no changes were observed caused by these two individual build jobs.

Mechanical testing of the printed specimens showed that, as already mentioned in numerous other studies, there is an effect of the building direction. Thereby, vertically built specimens show a lower UTS and YS but higher elongation, which is assumed to be caused by different heat treatment states and residual stresses as well as columnar grain growth. The storage conditions before building, in contrast, did not result in any differences of the mechanical properties, the reason being rapid removal of humidity from the surface of the L718 AMPO powder in the dry inert atmosphere present in the building chamber, which was also observed under different conditions in [26].

By examining the built cubes, it was shown that the roughness $\left(R_{a}\right)$ of the top face was smoother the more right it was positioned on the building platform (i.e. from where the spreading recoater blade comes). It is assumed that this is caused by segregation in the spread powder layer, in a way that initially smaller particles are left in the powder bed and coarser ones towards the end. By investigating the roughness of the side faces, it was observed that the cubes are mostly smoother on the side from which the powder is spread. With respect to the roughest side, however, no such correlation could be found. Regarding the density and porosity, the built cubes were de facto fully dense (99.971\%). The measured hardness was significantly higher inside the cube than at the edges, which is assumed to be caused by an intrinsic heat treatment that occurs during production. Investigating the microstructure showed that fine cellular dendrites were formed, which suppress the growth of secondary arms. Further it was shown that, in the interdendritic space, the strengthening alloying element $\mathrm{Nb}$ is enriched, which, due to rapid solidification and cooling, had no time to precipitate in the $\gamma$ matrix and form the strengthening phase but remains in undercooled solid solution. Therefore, the microstructure lacks strengthening precipitates.

Considering the chemical composition of the IN718 alloy it was shown that neither of the powders nor one of the printed specimens was changed by both build jobs performed.

Funding. Open access funding provided by TU Wien (TUW).

Open Access This article is licensed under a Creative Commons Attribution 4.0 International License, which permits use, sharing, adaptation, distribution and reproduction in any medium or format, as long as you give appropriate credit to the original author(s) and the source, provide a link to the Creative Commons licence, and indicate if changes were made. The images or other third party material in this article are included in the article's Creative Commons licence, unless indicated otherwise in a credit line to the material. If material is not included in the article's Creative 
Commons licence and your intended use is not permitted by statutory regulation or exceeds the permitted use, you will need to obtain permission directly from the copyright holder. To view a copy of this licence, visit http://creativecommons.org/licenses/by/4.0/.

\section{References}

1. Patterson, R.; Cox, A.; Reuth, E. V.: Rapid Solidification Rate Processing and Application to Turbine Engine Materials, JOM, 32 (1980), pp 34-39

2. Raj, B. A.; Jappes, J. T. W.; Khan, M.A.; et al.: Direct Metal Laser Sintered (DMLS) process to develop Inconel 718 alloy for turbine engine components, Optik, 202 (2020), 163735

3. Pollock, T. M.; Tin, S.: Nickel-Based Superalloys for Advanced Turbine Engines: Chemistry, Microstructure and Properties, Journal of Propulsion and Power, 22 (2006), pp 361-374

4. Ariaseta, A.; Kobayashi, S.; Takeyama, M.; et al.: Characterization of Recrystallization and Second-Phase Particles in Solution-Treated Additively Manufactured Alloy 718, Metallurgical and Materials Transactions A, 51 (2019), pp 973-981

5. Deng, D.; Eriksson, R.; Peng, R. L.; et al.: On the Dwell-Fatigue Crack Propagation Behavior of a High-Strength Ni-Base Superalloy Manufactured by Selective Laser Melting, Metallurgical and Materials Transactions A, 51 (2019), pp 962-972

6. Deng, D.; Peng, R. L.; Brodin, H.; et al.: Microstructure and mechanical properties of Inconel 718 produced by selective laser melting: Sample orientation dependence and effects of post heat treatments, Materials Science \& Engineering A, 713 (2018), pp 294-306

7. Ni, M.; Chen, C.; Wang, X.; et al.: Anisotropic tensile behavior of in situ precipitation strengthened Inconel 718 fabricated by additive manufacturing, Materials Science \& Engineering A, 701 (2017), pp 344-351

8. Xiao, H.; Li, S.; Han, X.; et al.: Laves phase control of Inconel 718 alloy using quasi-continuous-wave laser additive manufacturing, Materials \& Design, 122 (2017), pp 330-339

9. Szemkus, S.; Jahn, S.; Matthes, S.; et al.: Avoiding Humidity Influences for Robust Powder Bed Fusion Processing, Proceedings of EuroPM2017 Congress \& Exhibition, Milan, Italy, European Powder Metallurgy Association (EPMA), Shrewsbury, UK, 2017, Paper number 3684646

10. Cordova, L.; Campos, M.; Tinga, T.: Assessment of moisture content and its influence on laser beam melting feedstock, Proceedings of Euro PM2017 Congress \& Exhibition, Milan, Italy, European Powder Metallurgy Association (EPMA), Shrewsbury, UK, 2017, Paper number 3684585

11. Lefebvre, L.-P.; Bernier, F.; Orsoni-Wiemer, N.; et al.: Rheology of Powders: Assessing the Robustness and Impact of Humidity, Tribocharging, Particle Size and Composition, Proceedings of: Euro PM2019 Congress \& Exhibition, Maastricht, Netherlands, European Powder Metallurgy Association (EPMA), Shrewsbury, UK, 2019, Paper number 4342266

12. Olsson, E.; Sundin, S.; Karlsson, L.; et al.: Evaluation of Flowability Measurement Methods and Investigation of Influencing Factors for Flowability of Metal Powders for Additive Manufacturing; Proceed- ings of Euro PM2019 Congress \& Exhibition, Maastricht, Netherlands, European Powder Metallurgy Association (EPMA), Shrewsbury, UK, 2019, Paper number 4346392

13. Mellin, P.; Zavalis, T.; Tingö, L.; et al.: Moisture content analysis of metal powders using oven desorption followed by Karl Fischer titration, Metal Powder Report, 75 (2019), pp 34-39

14. LPW Technology: Moisture Analysis of Metal Powder Samples by Karl Fischer Titration; Brochure, Runcorn, United Kingdom, 2017

15. Greenspan, L.: Humidity Fixed Points Of Binary Saturated Aqueous Solutions, J Res Natl Bur Stand Sect A Phys Chem, A, 81 (1977), pp 89-96

16. Sun, Y. Y.; Gulizia, S.; Oh, C. H.; et al.: (2016), The Influence of AsBuilt Surface Conditions on Mechanical Properties of Ti-6Al-4V Additively Manufactured by Selective Electron Beam Melting, JOM, 68 (2016), pp 791-798

17. Edwards, P.; Ramulu, M.: Fatigue performance evaluation of selective laser melted Ti-6Al-4V, Materials Science and Engineering: $\mathrm{A}$ 598 (2014), pp 327-337

18. Greitemeier, D.; Dalle Donne, C.; Syassen, F; et al.: Effect of surface roughness on fatigue performance of additive manufactured Ti-6Al-4V, Materials Science and Technology, 32 (2016), pp 629-634

19. Wycisk, E.; Solbach, A.; Siddique, S.; et al.: Effects of Defects in Laser Additive Manufactured Ti-6AI-4V on Fatigue Properties, Physics Procedia, 56 (2014), pp 371-378

20. Spierings, A. B.; Starr, T. L.; Wegener, K.: (2013), Fatigue performance of additive manufactured metallic parts, Rapid Prototyping Journal, 19 (2013), pp 88-94

21. Mitterlehner, $\mathrm{M}$ : Danninger, $\mathrm{H}$.: Gierl-Mayer, $\mathrm{C}$; et al: Study on the flowability of gas atomized high alloy powders for Additive Manufacturing, Proceedings of Euro PM2017 Congress \& Exhibition, Milan, Italy, European Powder Metallurgy Association (EPMA), Shrewsbury, UK, 2017, Paper number 3686281

22. Kasperovich, G.; Hausmann, J.: Improvement of fatigue resistance and ductility of TiAl6V4 processed by selective laser melting, Journal of Materials Processing Technology, 220 (2015), pp 202-214

23. Li, X.; Shi, J. J.; Wang, C. H.; et al.: Effect of heat treatment on microstructure evolution of Inconel 718 alloy fabricated by selective laser melting, Journal of Alloys and Compounds, 764 (2018), pp 639-649

24. Li, J.; Zhao, Z.; Bai, P.; et al.: Microstructural evolution and mechanical properties of IN718 alloy fabricated by selective laser melting following different heat treatments, Journal of Alloys and Compounds, 772 (2019), pp 861-870

25. Popovich, V. A.; Borisov, E. V.; Popovich, A. A.; et al.: Impact of heat treatment on mechanical behaviour of Inconel 718 processed with tailored microstructure by selective laser melting, Materials \& Design, 131 (2017), pp 12-22

26. Mitterlehner, M.; Danninger, H.; Gierl-Mayer, C.; et al.: Investigation of the Influence of Powder Moisture on the Spreadability Using the Spreading Tester, BHM Berg- und Hüttenmännische Monatshefte, this issue

Publisher's Note. Springer Nature remains neutral with regard to jurisdictional claims in published maps and institutional affiliations. 